Psychology of Language and Communication 2017, Vol. 21, No. 1

DE GRUYTER

OPEN

DOI: $10.1515 /$ plc-2017-0003

MONIKA OBRĘBSKA, JOANNA ZINCZUK-ZIELAZNA

Adam Mickiewicz University, Poznań

\title{
EXPLAINERS AS AN INDICATOR OF DEFENSIVE ATTITUDE TO EXPERIENCED ANXIETY IN YOUNG WOMEN DIFFERING IN THEIR STYLES OF COPING WITH THREATENING STIMULI
}

\begin{abstract}
This paper presents the results of a frequency analysis of causal conjunctions and explainers in the speech of persons categorised as low-anxious, high-anxious, and repressors, selected according to the criteria of Weinberger et al. (1979).

Ninety female students, assigned to three groups: high-anxious persons $(n=30)$, low-anxious persons $(n=30)$, and anxiety repressors $(n=30)$, gave a speech lasting several minutes concerning personality features that they liked or disliked in themselves.

The results strongly confirmed the hypothesis that there are differences in the frequency of use of causal conjunctions and explainers between repressors, high-anxious, and low-anxious individuals. Their number is highest in the utterances of repressors and lowest in the utterances of low-anxious individuals.

Our study demonstrates that the experiencing of anxiety does not in itself lead to an increase in the frequency of use of causal expressions. The key factor would appear to be a high level of defensiveness and absence of insight into one's emotional states, characteristic of repressors. This may lead to a need to rationalise and to seek possible causes for the state of anxiety, which is externalised linguistically through the use of a high number of causal expressions.
\end{abstract}

Key words: explainers, verbal behaviour, anxiety, defensiveness, styles of coping with threatening stimuli, repressors

\section{Introduction}

Levels of anxiety are most frequently diagnosed in psychological studies using test-based methods such as the popular State-Trait Anxiety Inventory (STAI) of Spielberger, Gorsuch, and Lushene (Wrześniewski, Sosnowski,

Address for correspondence: Monika Obrębska, Adam Mickiewicz University, Institute of Psychology, Szamarzewskiego 89, 60-568 Poznań, Poland. E-mail: obrebska@amu.edu.pl 
\& Matusik, 2002). An advantage of such methods is their ease of application, but a weakness is their declarative nature, which makes them susceptible to various kinds of conscious or unconscious attempts to falsify the results. To exclude these researchers often use untruthfulness scales, such as the popular Social Approval Scale (Crowne \& Marlowe, 1960, 1964) used in studies of psychometric orientation, where certain tests are verified in terms of their susceptibility to the effect of social approval and the possibility of falsification of the results by the subject. They are also used in tests to diagnose individual differences in the level of need for social approval and the associated tendency towards defensive repression or denial of the possession of undesirable features.

Analysing the results obtained by subjects on scales used to measure trait anxiety and tendency to react in a socially approved manner, Weinberger, Schwartz, and Davidson (1979) distinguished four groups of persons, differing in their style of coping with threatening stimuli: low-anxious persons, highanxious persons, repressors, and defensive high-anxious persons. In creating this typology, Weinberger et al. (1979) noticed that the group of persons achieving low scores on the anxiety scale was not homogeneous. It included both persons with genuinely low levels of anxiety and persons who reacted to stressful conditions with a high level of physiological and behavioural arousal in spite of having low declared levels of anxiety. Identifying and describing the latter group, the researchers proposed a new way of conceptualising the psychoanalytically based mechanism of repression. By considering repression in categories of a personality variable, i.e. as one of the coping styles, they enabled the use of the rich and precise methodology of cognitive psychology and an experimental approach to the testing of this phenomenon.

In our research, we decided to analyse the utterances of subjects selected according to the criteria of Weinberger et al. (1979) by questionnaire-based methods to compare the frequency of use of causal expressions, which are considered by many researchers (Weintraub \& Aronson, 1974; Natale, Dahlberg, \& Jaffe, 1978) to be one of the most reliable verbal indicators of state anxiety and defensiveness. We wished to investigate whether repressors use causal expressions more frequently than persons in the high-anxious and low-anxious groups, thus revealing - outside their conscious control - their anxiety and high level of defensiveness.

The paper is structured as follows. In Section 2, a concise review of the most relevant literature on lexical indicators of anxiety and defensiveness will be presented, and Section 3 will describe research into styles of coping with threatening stimuli. In Section 4, the methodology on which the present study is based will be described. The results of the analysis are discussed in Section 5, and Section 6 summarises the main findings and contains comments on their limitations and strengths. 


\section{Lexical indicators of anxiety and defensiveness}

Anxiety may be understood, firstly, as a transient and situationally conditioned emotional state that is manifested by specific physiological changes, such as raised pulse and breathing rate (e.g. Newton \& Contrada, 1992), expressive behaviour such as facial expressions (e.g. Zinczuk, 2008), and subjective experiences characterised by fears and cognitive unease. State anxiety is regarded as the emotional component of risk assessment behaviour (Blanchard \& Blanchard, 2008; Perkins et al., 2012), in contrast to fear or panic, which are viewed as the emotional accompaniment of flight. The second way of viewing anxiety is as a relatively stable personality trait that makes a person liable to perceive objectively unthreatening situations as threatening and to react to them with disproportionately strong states of anxiety. Trait anxiety is proposed to serve as a vulnerability factor for greater frequency and intensity of anxiety experiences, as well as the development of anxious pathology (Elwood et al., 2012). A popular questionnaire constructed to differentiate between state anxiety and trait anxiety is the STAI (Spielberger et al., 1983), which has been adapted to Polish by Wrześniewski and Sosnowski (2002).

In order to determine anxiety levels in the examined individuals, their lexical choices are analysed in addition to pencil-and-paper methods and physiological or behavioural indicators. It is assumed that the state of anxiety is unconsciously reflected in the structure of language, and that the lexical choices made by subjects are a good predictor of that state (Gottschalk, 2013; Saunders, 1974). In the context of a high level of anxiety, analyses have mostly focused on the use of the pronoun I (Brockmeyer et al., 2015; Bucci \& Freedman, 1981; Zimmermann et al., 2016), particles and negatives (Gawda, 2007; Mahl, 1987a; 1987b; Obrębska \& Zinczuk-Zielazna, 2016), and so-called cognitive words, i.e. words describing the processes of insight and arriving at understanding, which are an important indicator of a decreased level of anxiety and an improved state of mental health (Pennebaker, Mehl, \& Niederhoffer, 2003).

For Ertel (1985), the state of anxiety also manifests itself in a higher degree of dogmatisation of expressed messages, which has also been confirmed by the present authors' own study (Zinczuk-Zielazna \& Obrębska, 2016). The study showed that individuals with a high level of anxiety (conscious or repressed) use dogmatic expressions in their utterances (e.g. zawsze, wszyscy, nikt, calkowicie, trzeba, na pewno [always, everybody, nobody, totally, it's necessary, surely]) significantly more often, and non-dogmatic ones significantly less often than low anxious individuals, expressing doubts and a lack of confidence (e.g. czasem, rzadko, może, prawie, chyba [sometimes, rarely, perhaps, almost, maybe]). These results are consistent with the results of the classic research of Rokeach (1960), continued contemporarily for example by Rappaport (1978, 1979), Redfering (1979), and Johnson (2010). Those studies indicate that traits of the belief system externalised in the utterances of high-anxious individuals, such as excessive generalisation, rigidity, a sense of constraint, being closed 
to influence, isolation of beliefs, and a strong conviction about their truthfulness, can be recognised as a set of defensive reactions which are used for protection against anxiety.

Mahl(1987b), on the other hand, devoted much attention to pauses, disruptions, and "small" parts of speech such as pronouns, conjunctions, and particles, which in his opinion occur in utterances more often if a speaker is experiencing anxiety. He examined the utterances of patients during psychotherapy (Mahl, 1956), the language of children regarded as anxious (Zimbardo, Mahl, \& Barnard, 1963), and the spontaneous speech of healthy individuals in situations arousing anxiety (Kasl \& Mahl, 1965; Mahl, 1987a). He stated that the proportion of the number of disruptions to the overall number of uttered words is positively correlated with anxiety. The proportion may therefore be considered as a measure of a speaker's anxiety. This is also confirmed by the results of research on the lexical choices of individuals suffering from schizophrenia (Obrębska \& Obrębski, 2007): The number of particles, conjunctions, and pronouns in the utterances of sufferers was significantly larger than in the utterances of healthy individuals, which may be related to the high level of anxiety accompanying schizophrenia.

In turn, Argaman (2010) explored the possible relationships between the intensity of emotions and the lexical modalities for expressing those emotions. Based on an experiment in which subjects described the emotions experienced while watching films, he distinguished a number of verbal indicators of high emotional intensity, such as lexical intensifiers (e.g. most), lexical reducers (e.g. least), repetitions, use of the first person singular, similes and metaphors, exclamations, interjections, and descriptive emphasis. This experiment confirmed that significant differences exist between the lexical modalities found in texts produced with lower emotional intensity and those produced with greater emotional intensity.

In Poland, the effect of anxiety on the structure of utterances has been studied by, among others, Gawda (2007). In her research on antisocial personalities, she noted that a high level of anxiety is positively correlated with the length of narrative constructions, the frequency of description of actions, and the quantity of categorical expressions such as always, never, nothing, at all, which are linked to a lower tolerance of uncertainty and the need for immediate resolution of ambiguities and doubts.

In the present study, the authors decided to look into the subjects' utterances in terms of the use of conjunctions and expressions serving to define causality (the so-called explainers), which are regarded by many researchers as one of the most reliable indicators of anxiety. Weintraub and Aronson (1974) and Weintraub (1989) connect that use with a need for making excuses and seeking explanations, which intensifies due to the state of anxiety; Natale, Dahlberg, and Jaffe (1978), on the other hand, link it to a high degree of defensiveness ${ }^{1}$. Analysing the 1 The concept of defensiveness, initially identified with repression, was introduced to psychology by Sigmund Freud at the turn of the 20th century. He viewed it as an unconscious mechanism whereby threatening thoughts, images, feelings or desires were removed from the consciousness. He believed that defensiveness made it possi- 
utterances of participants in psychoanalytical sessions ${ }^{2}$, they noted that explainers become a frequent lexical attempt at defensive processing of experienced anxiety, being the externalisation of the psychological mechanism of rationalisation. In the course of the session and with a decreasing level of anxiety, the number of explainers in the utterances of the examined subjects also decreased.

These classical studies of lexical correlates of defensiveness are referenced by, among others, Gottschalk, Fronczek, and Bechtel (2004) and Gottschalk (2013). They analysed short 5-min speeches made by healthy subjects and by persons suffering from various psychological disorders (depression, schizophrenia, anxiety disorders) in terms of certain forms of speech (such variables as rate of speech, frequency and duration of pauses, frequency of incomplete words and of non-lexical vocalisations) and content (considerations of the meanings, relationships, objects, concepts, and processes symbolised by words), as well as the grammatical classifications of words (including adjectives, adverbs, nouns, pronouns, verbs, prepositions, conjunctions, and interjections). Their analyses show that, besides causal expressions, high levels of anxiety and defensiveness are also significantly correlated with verbal displacements and denials of anxiety, across different groups of subjects, ranging from mentally and physically healthy individuals to emotionally disturbed criminals and schizophrenic patients.

Defensiveness is defined in this context as the endorsement of socially desirable yet unlikely traits, as well as the denial of common yet undesirable traits (Crowne \& Marlowe, 1960, 1964). Defensive individuals seem to selectively "repress", "defend against", or direct attention away from threatening stimuli, avoid unpleasant information, and deny experiencing negative emotions such as anxiety (Temple \& Cook, 2007). According to the vigilance-avoidance theory (Derakshan, Eysenck, \& Myers, 2007), people with defensive tendencies initially exhibit a rapid reaction of vigilance with respect to stimuli that pose a threat to their self-image. This early reaction triggers physiological changes and expressive behaviours. There then follows a process of avoidance of threatening stimuli, involving the action of specific avoidant cognitive biases (attentional, interpretive, and memory) that inhibit the conscious experience of anxiety.

None of the aforementioned studies of verbal indicators of anxiety analysed the influence of individual variables, connected with type of personality or style of coping with experienced anxiety, on the verbal behaviour and lexical choices of the examined individuals. In the present study, the authors decided to differentiate the examined groups, taking into account different styles of coping with threatening stimuli in accordance with the typology proposed by Weinberger, Schwartz, and Davidson (1979). Analysing the subjects' results on scales measuring anxiety traits and inclination to react in a socially approved manner,

ble to avoid anxiety and unpleasantness, but also caused distorted perception, making it difficult or impossible to solve problems, and blocked the possibility of unloading the excess of excitement generated by impulsive feelings and desires.

2 The researchers analysed spontaneous utterances of 7 patients ( 4 men and 3 women) for 1 year and a half of psychotherapy (3 sessions a week). 
they distinguished four groups differing in their style of coping with threatening stimuli: truly low-anxious individuals, high-anxious individuals, repressors, and defensive high-anxious individuals.

\section{Styles of coping with threatening stimuli}

Issues of anxiety, particularly that of the mutual relationship between the dimensions of trait anxiety and state anxiety, would appear to be of key importance for understanding the way of functioning of people representing the coping styles described by Weinberger et al. (1979). The first group consists of low-anxious persons, who return low scores on scales of both trait anxiety and social desirability (defensiveness), which points to a lack of inclination to falsify the results of tests towards a better psychological adaptation. Low-anxious individuals are marked by a low level of anxiety both in self-reporting and by other indicators of the emotional process: behavioural and physiological. High-anxious individuals, on the other hand, are characterised by a high intensity of anxiety and low social desirability (defensiveness). In stressful situations these individuals strongly experience a state of anxiety, which is usually conscious and expressed, for example by disclosing details from their private life which are not required in the study (Myers, 2010).

Another group is individuals using repression (repressors) who score low on the anxiety trait scale and high on social desirability scales (defensiveness). They show a low inclination to consciously experience anxiety during a distressing task, but simultaneously display high anxiety through physiological and behavioural indicators (Asendorph \& Scherer, 1983; Derakshan \& Eysenck, 1997, 2001a, 2001b; Myers, 2000, 2010). An interesting trend in research on this subject concerns the question of whether repressors avoid threatening stimuli intentionally and consciously or in an automatic and unconscious way. This dilemma remains unsolved (cf. Zinczuk \& Draheim, 2009). Some researchers (Weinberger \& Davidson, 1994) assume that repressors report experiencing a substantially lower intensity of emotions as compared to the level of physiological and expressive arousal because they avoid experiencing emotions on a conscious level, perform defensive self-deception and are deeply convinced that they are not inclined to experience anxiety and other negative emotions. However, other researchers (Baumeister \& Cairns, 1992) assume that people described as repressive may in some situations purposefully estimate their level of anxiety below that which is actually experienced and intentionally control the impression they give, presenting themselves more favourably.

The final group consists of defensive high-anxious individuals scoring highly on both the scale of anxiety traits and that of social desirability (defensiveness). So far, this group is the least well known. Defensive high-anxious individuals are described as experiencing embarrassment and worry and expressing discomfort in situations involving the disclosure of information required in studies.

The above characteristics are summed up in Figure 1. 

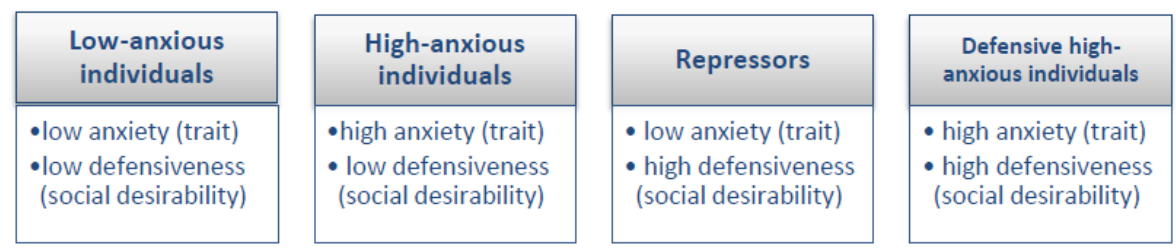

Figure 1. Four styles of coping with threatening stimuli as defined by Weinberger et al. (1979).

In seeking indicators of experienced anxiety, researchers have most frequently used methods measuring the physiological aspect of emotions (e.g. heartbeat) or various types of expressive behaviour (e.g. facial expression). In this study, the authors decided to analyse utterances of the subjects, which may, in a manner beyond their control, reveal their state of anxiety. The authors analysed the texts of utterances of three out of four groups of individuals selected according to the criteria of Weinberger, Schwartz, and Davidson - low-anxious individuals, individuals with a repressive style of coping with threatening stimuli, and high-anxious individuals - to compare the frequency of use of conjunctions and explainers, which are considered to be an important indicator of anxiety. The authors assumed, in accordance with the research of Weintraub and Aronson (1974), Weintraub (1989), and Natale, Dahlberga, and Jaffe (1978), that the number of these expressions is largest in the utterances of repressors, who have high anxiety and high defensiveness, and lowest in the utterances of lowanxious individuals. This is reflected in the following research hypothesis:

H1. There exist differences in the frequency of use of causal conjunctions and explainers between repressors, high-anxious, and low-anxious individuals: The number is highest in the utterances of repressors and lowest in the utterances of low-anxious individuals.

\section{Method}

\section{Participants}

To investigate the above hypothesis, the authors conducted a study consisting of two stages. The goal of the survey stage was to select groups of individuals representing the coping styles defined by Weinberger et al. and to obtain initial data on differences between the groups. The participants were 570 students of 14 different fields (special teacher training, general teacher training, philosophy, political science, cognitive science, biology, geography, environmental protection, Polish, English, history, musicology, art history, and archaeology). Their average age was 21. The respondents completed the Spielberger et al. STAI as adapted to Polish by Wrześniewski et al. (2002) and the Marlowe-Crowne Social Approval Scale as adapted to Polish by Siuta (1989).

The laboratory stage of the study involved 90 women each selected (from 
the initial group of 570 persons) and classified into one of the three groups high-anxious individuals $(n=30)$, repressors $(n=30)$, and low-anxious individuals $(n=30)$ - on the basis of the results scored in the STAI and the MarloweCrowne Social Desirability Scale, differing by one standard deviation from the average. Since cluster analysis using the $k$-means method did not show a cluster characteristic of defensive high-anxious individuals, that group was not included in the study.

The gender variable is significant when considering the predisposition to experience anxiety. Some studies show women to have higher levels of anxiety than men; for example, in a study by Noël et al. (2013) women exhibited significantly higher levels than men according to the Anxiety Sensitivity Index (ASI; Reiss, Peterson, Gursky, \& McNally, 1986) and the Penn State Worry Questionnaire (PSWQ; Meyer, Miller, Metzger, \& Borkovec, 1990). Similarly, a study by Keogh (2004) confirmed the assumption that there are differences between men and women in anxiety sensitivity - women reported higher levels of AS than men. There is evidence that gender can moderate the strength of correlation between implicit and explicit measures; for example, Donges et al. (2015) found a link between attachment anxiety and implicit self-concept of neuroticism in women but not in men. It was therefore decided to restrict the present study group to women only. Men will be tested in a separate study, which will consequently enable the identification of possible differences between the sexes in the propensity to use explainers in situations where anxiety is experienced.

\section{Procedure}

Participants $(N=90)$ were assigned a task which might be potentially stressful: giving a speech of several minutes in front of a two-person audience composed of experts (psychologists). The speech was intended to concern personality traits of the subject which the subject liked and disliked. The subject had about $10 \mathrm{~min}$ to prepare the speech, and then entered another room where the audience was waiting. After the stage of speaking freely, the subject was asked eight standard questions (the same for all participants) by members of the audience:

1. Is there any other feature of your personality that you do not like?

2. Is there any other feature of your personality that you like?

3. In your opinion, what features do people like about you?

4. In your opinion, what features do people not like about you?

5. Please reveal some negative aspect of yourself that your friends are not aware of.

6. Do you consider yourself attractive?

7. Is this conversation difficult for you?

8. Do you want to add something?

The subjects were not told in advance that they would be asked questions by the audience of experts. It was expected that this part of the procedure might 
lead to a fuller expression of the utterance patterns characteristic of the particular types of person, since the subjects would be constructing their utterances spontaneously without the possibility of prior consideration and preparation. The first four questions were requests for expansion on the topic of the subject's personality features, while Questions 5, 6, and 7 were constructed to be potentially embarrassing and thus stressful to the subject. The speech was recorded with the use of a digital video camera whose presence constituted another potentially distressing factor. All study participants were informed about the video-recording before the experiment and provided written consent.

\section{Measuring techniques}

The texts of the recorded speeches were transcribed in the format used by the Transcriber program. A specially developed computer application automatically marked causal conjunctions and explainers in the copied texts. The study took into account those that are most frequent in the Polish language: bo, poniewaz, gdyż, w zwiazku z tym, w zwiazku z czym, dzięki temu, dlatego że, z tego względu [because, as, since, in connection with that, thanks to this, that's why, because of that] (Bąk, 1993). The marking automatically added by the software required manual verification, which was carried out by two specialists (academics with language doctorates) in consultation with each other.

\section{Results}

The reliability of the questionnaires, measured using Cronbach's Alpha, was satisfactory:

- for the Spielberger et al. STAI as adapted to Polish by Wrześniewski et al. (2002), $\alpha=.87$;

- for the Marlowe-Crowne Social Approval Scale as adapted to Polish by Siuta (1989), $\alpha=.74$.

The study calculated the proportion of causal conjunctions and explainers among all words used in the text, separately for each individual. Then the result was averaged within the three groups of individuals under study: low-anxious individuals, high-anxious individuals, and repressors. The obtained mean values and standard deviations are shown in Table 1.

Table 1. Mean values and standard deviation for causal conjunctions and explainers

\begin{tabular}{ccc}
\hline Group & Mean values & Standard deviation values \\
\hline Low-anxious individuals & 0.006 & 0.004 \\
High-anxious individuals & 0.008 & 0.004 \\
Repressors & 0.015 & 0.008 \\
\hline
\end{tabular}


Mean values for particular groups are presented in Figure 2.

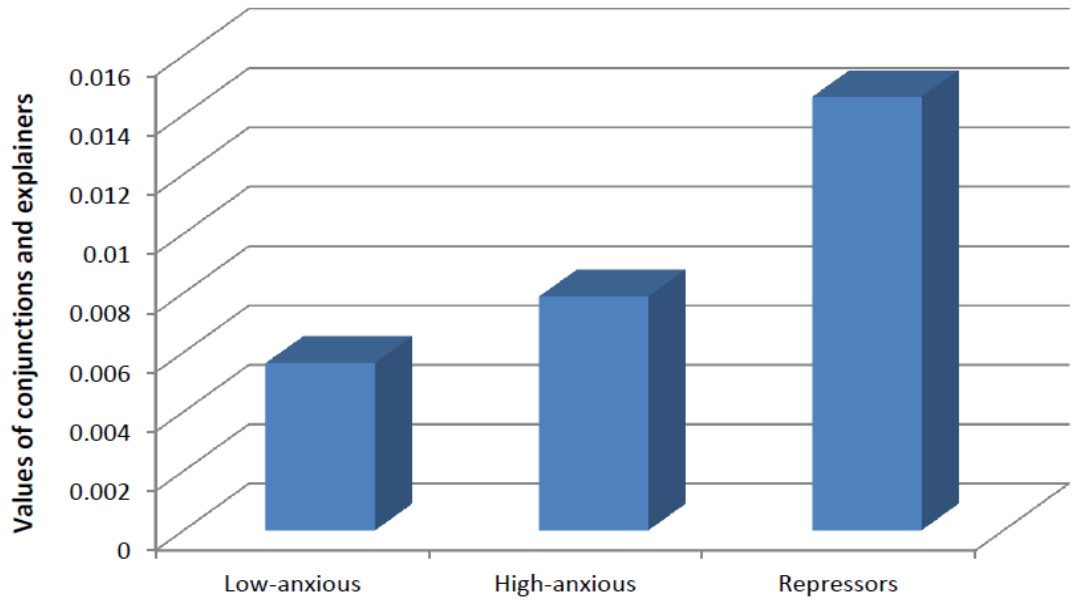

Figure 2. Numbers of conjunctions and explainers

The highest number of causal conjunctions and explainers was recorded in the speech of repressors, and the lowest in the utterances of lowanxious individuals, which is consistent with the statement of hypothesis H1 pertaining to the differences in expressing causality between the examined groups. The differences between groups were significant: $F(2,87)=20.18, p<.001$. The least homogeneous group, with the most dispersed results, was the repressors; the standard deviation values for the other groups proved to be the same.

Tukey's post hoc HSD test was used to determine the level of significance of the differences identified between the low-anxious group (la), the high-anxious group (ha), and the repressors (r). The results are given in Table 2; statistically significant results for $p<.05$ are marked in bold.

Table 2. The results of statistical significance for conjunctions and explainers

\begin{tabular}{ccccc}
\hline Groups & Difference & $\begin{array}{c}\text { Lowerconfidence } \\
\text { interval }\end{array}$ & $\begin{array}{c}\text { Upperconfidence } \\
\text { interval }\end{array}$ & $\begin{array}{c}\text { Statistical } \\
\text { significance }\end{array}$ \\
\hline r-la & $\mathbf{0 . 0 0 9}$ & $\mathbf{0 . 0 0 5}$ & $\mathbf{0 . 0 1 2}$ & $\boldsymbol{p}<\mathbf{0 . 0 0 1}$ \\
ha-la & 0.002 & -0.001 & 0.006 & $p=0.284$ \\
ha-r & $\mathbf{- 0 . 0 0 7}$ & $\mathbf{- 0 . 0 1 0}$ & $\mathbf{- 0 . 0 0 3}$ & $\boldsymbol{p}<\mathbf{0 . 0 0 1}$ \\
\hline
\end{tabular}

Statistically significant differences occurred between repressors and low- and high-anxious individuals. The calculated effect sizes point to a very strong relation between the variables $(d>1)$. This means that there is a strong relationship between the inclination to repress and the frequency of use of causal conjunctions and explainers. The difference between low-anxious and highanxious individuals proved to be non-significant. 


\section{Conclusions}

The results obtained in this study strongly confirm the hypothesis that there are differences in the frequency of use of causal conjunctions and explainers between repressors, high-anxious, and low-anxious individuals. Their number is highest in the utterances of repressors and lowest in the utterances of lowanxious individuals. The differences between the repressors and the other two groups are statistically significant, and the calculated effect sizes indicate a very strong relation between the variables.

The results of the experiment confirm the relationship between frequency of use of causal conjunctions and explainers and a high level of defensiveness, which was also observed by Weintraub and Aronson (1974) and Natale, Dahlberg, and Jaffe (1978). The highest rate of explainers occurred among repressors, who are characterised by an inclination to block the perception of a threat and to deny negative emotions; the lowest rate, on the other hand, was found among lowanxious individuals, who have a low level of anxiety and low defensiveness.

Weintraub (1989) and the other above-mentioned researchers assumed a dependence between the intensity of anxiety and defensiveness: the higher the level of anxiety, the higher the defensiveness and the more frequent the use of explainers. Natale et al. (1978) observed that when the intensity of anxiety decreased as a result of successful psychotherapy, there was also a decrease in the number of explainers in the patients' utterances. The present study shows that the dependence is not as simple as suggested in the above-mentioned work: experiencing anxiety itself does not lead to an increase in the frequency of use of explainers. In this experiment, the results of high-anxious individuals were not significantly different from those of low-anxious individuals.

\section{Discussion}

The lack of insight into one's own emotional states during high anxiety arousal, characteristic for repressors, seems here to be crucial to understanding the structure and significance of the obtained results. These individuals, according to the results of Asendorph and Scherer (1983), display a low inclination to experience anxiety consciously, but at the same time show high anxiety through physiological and behavioural indicators. Similarly, in the present study repressors scored low results on a self-reporting scale of anxiety traits and high scores in the behavioural dimension of expressing causality. Denial of negative emotions, characteristic for repressors, makes it impossible to cope adequately with these emotions, which may result in defensive self-deception. Repressors experience physiological arousal and do not connect it with the state of anxiety, which may result in the need for rationalisation and a seeking of possible causes of their state of anxiety.

A similar cognitive mechanism for dealing with anxiety occurs in depressive 
states and anxiety disorders (Iqbal \& Dar, 2015; Modini \& Abbott, 2016; Young \& Dietrich, 2015). Referring to depression, Nolen-Hoeksema et al. (1991, 1993, 2008) refer simply to "obsessive ruminations" which manifest themselves through, for example, a constant need to analyse the causes of the state. Our study has shown that the absence of insight into experienced emotions and a tendency to deny them and to perform defensive self-deception, characteristic for repressors, may further intensify the ruminative need to seek causes and explanations. In stressful situations (as in our experiment) repressors feel arousal but do not connect it with anxiety, perceiving themselves as low-anxiety individuals. It may be assumed that linguistic explainers reflect an unconscious attempt to understand the causes of the arousal. Consciousness of experienced anxiety makes it easier to understand it and to make rational attempts to deal with it; absence of such consciousness favours only rationalisations.

This result naturally requires verification and further research using a larger and more diverse sample, with the consideration of other variables such as depressiveness and the intensity of ruminations, verbal intelligence, extraversion and other personality traits. Another interesting direction of investigation would be to seek a dependence between lexical choices and state of anxiety, which could be examined with more objective methods such as physiological or behavioural indicators as in the Facial Action Coding System (Ekman \& Friesen, 1978; Ekman, Friesen, \& Hager, 2002). In addition, it would be profitable to analyse the different lexical indicators of anxiety that are described in the literature, which may be a good starting point for further empirical research and theoretical analyses.

\section{References}

Argaman, O. (2010). Linguistic markers and emotional intensity. Journal of Psycholinguistic Research, 39(2), 89-99. doi: 10.1007/s10936-009-9127-1

Asendorph, J. A., \& Scherer, K. R. (1983). The discrepant repressor: Differentiation between low anxiety, high anxiety and repression of anxiety by autonomic-facial-verbal patterns of behavior. Journal of Personality and Social Psychology, 45, 1334-1346. doi: 10.1037/0022-3514.45.6.1334

Baumeister, R. F., \& Cairns, K. J. (1992). Repression and self-presentation: When audiences interfere with self-deceptive strategies. Journal of Personality and Social Psychology, 62(3), 651-662.

Bąk, P. (1993). Gramatyka języka polskiego [Polish Grammar]. Warsaw: Wydawnictwo Wiedza Powszechna.

Blanchard, D. C., \& Blanchard, R. J. (2008). Defensive behaviors, fear and anxiety. In R. J. Blanchard, D. C. Blanchard, G. Griebel, \& D. Nutt (Eds.), Handbook of Anxiety and Fear (Vol. 17, pp. 63-79). Amsterdam: Academic Press. doi:10.1016/S1569-7339(07)00005-7 
Brockmeyer, T., Zimmermann, J., Kulessa, D., Hautzinger, M., Bents, H., Friederich, H. C., Herzog, W., \& Backenstrass, M. (2015). Me, myself, and I: Self-referent word use as an indicator of self-focused attention in relation to depression and anxiety. Frontiers in Psychology, 6, 1564. doi: 10.3389/ fpsyg.2015.01564

Bucci, W., \& Freedman, N. (1981). The language of depression. Bulletin of the Menninger Clinic, 45(4), 334-358.

Crowne, D. P., \& Marlowe, D. (1960). A new scale of social desirability independent of psychopathology. Journal of Consulting Psychology, 24(4), 349-354. doi: 10.1037/h0047358

Crowne, D. P., \& Marlowe, D. A. (1964). The approval motive: Studies in evaluative dependence. New York, NY: Wiley. doi: 10.1016/00224405(65)90048-8

Derakshan, N., \& Eysenck, M. W. (1997). Interpretive biases for one's own behavior and physiology in high-trait anxious individuals and repressors. Journal of Personality and Social Psychology, 73(4), 816-825.

Derakshan, N., \& Eysenck, M. W. (2001a). Effects of focus of attention on experienced anxiety in high-anxious, low-anxious, defensive high-anxious, and repressor individuals. Anxiety, Stress, \& Coping, 14(3), 285-300.

Derakshan, N., \& Eysenck, M. W. (2001b). Manipulation of focus of attention and its effects on anxiety in high-anxious individuals and repressors. Anxiety, Stress, \& Coping, 14(2), 173-191.

Derakshan N., Eysenck M. W., \& Myers L. B. (2007). Emotional information processing in repressors: The vigilance avoidance theory. Cognition \& Emotion, 21(8), 1585-1614. doi: 10.1080/02699930701499857

Donges, U. S., Jachmann, A., Kersting, A., Egloff, B., \& Suslow, T. (2015). Attachment anxiety and implicit self-concept of neuroticism: Associations in women but not men. Personality \& Individual Differences, 72, 208-213. doi: 10.1016/j.paid.2014.08.043

Ekman, P., \& Friesen, W. V. (1978). Facial Action Coding System (FACS): A technique for the measurement of facial actions. Palo Alto, CA: Consulting Psychologists Press.

Ekman, P., Friesen, W. V., \& Hager, J. C. (2002). Facial Action Coding System. The Manual on CD ROM. Salt Lake City, UT: Research Nexus division of Network Information Research Corporation.

Elwood, L. S., Wolitzky-Taylor, K., \& Olatunji, B. O. (2012). Measurement of anxious traits: A contemporary review and synthesis. Anxiety, Stress, \& Coping, 25(6), 647-666. doi: 10.1080/10615806.2011.582949

Ertel, S. (1986). Language, thought and culture: Toward a mergence of diverging problem fields. In I. Kurcz, G. W. Shugar, \& J. H. Danks (Eds.), Knowledge and Language (pp. 139-163). Amsterdam: Elsevier Science Publishers.

Gawda, B. (2007). Ekspresja pojęć afektywnych wnarracjach osób z osobowościa antyspoleczna [Affective constructs expression in the narrations of people 
with antisocial personality]. Lublin: Wydawnictwo Uniwersytetu Marii Curie-Skłodowskiej.

Gottschalk, L. A. (2013). Content Analysis of Verbal Behavior: New Findings and Clinical Applications. New York, NY: Routledge.

Gottschalk, L. A., Fronczek, J., \& Bechtel, R. J. (2004). Defense mechanisms and hope as protective factors in physical and mental disorders. In G. Smith, J. G. Draguns, \& W. Ehlers (Eds.), Defense Mechanisms: Theoretical, Research and Clinical Perspectives (pp. 453-476). Oxford: Elsevier Science Publishers. doi: 10.1016/S0166-4115(04)80045-1

Iqbal, N., \& Dar, K. A. (2015). Negative affectivity, depression and anxiety: Does rumination mediate the links? Journal of Affective Disorders, 181(1), 18-23. doi: 10.1016/j.jad.2015.04.002

Johnson, J. J. (2010). Beyond a shadow of doubt: The psychological nature of dogmatism. The International Journal of Interdisciplinary Social Sciences, 5(3), 1833-1882.

Kasl, S. V., \& Mahl, G. F. (1965). The relationship of disturbances and hesitations in spontaneous speech to anxiety. Journal of Personality and Social Psychology, 1(5), 425-433. doi: 10.1037/h0021918

Keogh, E. (2004). Investigating invariance in the factorial structure of the anxiety sensitivity index across adult men and women. Journal of Personality Assessment, 83(2), 153-160.

Mahl, G. F. (1956). Disturbances and silences in the patient's speech in psychotherapy. Journal of Abnormal Psychology, 53(1), 1-15. doi: 10.1037/ h0047552

Mahl, G. F. (1987a). Everyday Disturbances of Speech. New York, NY: Plenum Press.

Mahl, G. F. (1987b). Explorations in Nonverbal and Vocal Behavior. Hillsdale, NJ: Lawrence Erlbaum Associates.

Modini, M., \& Abbott, M. J., (2016). A comprehensive review of the cognitive determinants of anxiety and rumination in social anxiety disorder. Behaviour Change, 33(3), 150-171. doi: 10.1017/bec.2016.10

Meyer, T. J., Miller, M. L., Metzger, R. L., \& Borkovec, T. D. (1990). Development and validation of the Penn State Worry Questionnaire. Behaviour Research and Therapy, 28, 487-495. doi: 10.1016/0005-7967(90)90135-6

Myers, L. B. (2000). Identifying repressors: A methodological issue for health psychology. Psychology and Health, 15(2), 205-214.

Myers, L. B. (2010). The importance of the repressive coping style: Findings from 30 years of research. Anxiety, Stress, \& Coping, 30(1), 3-17. doi: 10.1080/10615800903366945

Natale, M., Dahlberg, C. C., \& Jaffe, J. (1978). The relationship of defensive language behavior in patient monologues to the course of psychoanalysis. Journal of Clinical Psychology, 34(2), 466-470.

Newton, T. L., \& Contrada, R. J.,(1992). Repressive coping and verbal-autonomic 
response dissociation: The influence of social context. Journal of Personality and Social Psychology, 62(1), 159-167.

Noël, V. A., Lewis, K., Francis, S. E., \& Mezo, P. G. (2013). Relationships between the multiple dimensions of anxiety sensitivity and symptoms of anxiety and depression in men and women. Journal of Cognitive and Behavioral Psychotherapies, 13(2), 333-353.

Nolen-Hoeksema, S. (1991). Responses to depression and their effects on the duration of depressive episodes. Journal of Abnormal Psychology, 100(4), $569-582$.

Nolen-Hoeksema, S., \& Morrow, J. (1993). Effects of rumination and distraction on naturally occurring depressed mood. Cognition and Emotion, 7, 561-570. doi: 10.1080/02699939308409206

Nolen-Hoeksema, S., Wisco, B. E., \& Lyubomirsky, S. (2008). Rethinking rumination. Perspectives on Psychological Science, 3(5), 400-442. doi: 10.1111/j.1745-6924.2008.00088.x

Obrębska, M., \& Obrębski, T. (2007). Lexical and grammatical analysis of schizophrenic patients' language: A preliminary report. Psychology of Language and Communication, 11(1), 63-72.

Obrębska, M., \& Zinczuk-Zielazna, J. (2016). Style radzenia sobie z bodźcami zagrażającymi a częstość użycia partykuł w wypowiedziach jako wskaźnik lęku w sytuacji społecznej ekspozycji [Styles of coping with threatening stimuli and frequency of the use of particles in speech as an indicator of anxiety in a situation of public exposure]. Socjolingwistyka, 30, 261-275.

Pennebaker, J. W., Mehl, M. R., \& Niederhoffer, K. (2003). Psychological aspects of natural language use: Our words, our selves. Annual Review of Psychology, 54(1), 547-577.

Perkins, A. M., Inchley-Mort, S. L., Pickering, A. D., Corr, P. J., \& Burgess, A. P. (2012). A facial expression for anxiety. Journal of Personality and Social Psychology, 102(5), 910-924.

Rappaport, E. (1978). The effects of dogmatism and anxiety on changes in religious identification. The Journal of Social Psychology, 104(1), 141-142. doi: 10.1080/00224545.1978.9924049

Rappaport, E. (1979). Effects of dogmatism on state anxiety during the analysis and synthesis of new beliefs. Journal of Personality Assessment, 43(3), 284288.

Redfering, D. L. (1979). Relationship between attitudes toward feminism and levels of dogmatism, achievement and anxiety. The Journal of Psychology, 101(2), 297-304.

Reiss, S., Peterson, R. A., Gursky, D. M., \& McNally, R. J. (1986). Anxiety sensitivity, anxiety frequency and the predictions of fearfulness. Behaviour Research and Therapy, 24, 1-8. doi: 10.1016/0005-7967(86)90143-9

Rokeach, M. (1960). The open and closed mind. Investigation into nature of belief systems and personality systems. New York, NY: Basic Books. 
Saunders, T. R. (1974). Effects of trait anxiety on noncontent verbal behavior in a standardized interview. Journal of Clinical Psychology, 30(2), 137-142.

Siuta, J. (1989). Zmienna aprobaty społecznej w badaniach nad zjawiskami hipnotycznymi [Social approval variable in studies of hypnotic phenomena]. Zeszyty Naukowe UJ, 5, 131-141.

Spielberger, C. D., Gorsuch, R. L., Lushene, R. E., Vagg, P. R., \& Jacobs, G.A. (1983). Manual for the State-Trait Anxiety Inventory: STAI (Form Y2). Palo Alto, CA: Consulting Psychologists Press.

Temple, R. O., \& Cook, E. W. (2007). Anxiety and defensiveness: Individual differences in affective startle modulation. Motivation \& Emotion, 31(2), 115-123. doi: 10.1007/s11031-007-9062-0

Weinberger, D. A., \& Davidson, M. N. (1994). Styles of inhibiting emotional expression: Distinguishing repressive coping from impression management. Journal of Personality, 62(4), 587-613. doi: 10.1111/j.1467-6494.1994. tb00310.x

Weinberger, D. A., Schwartz, G. E., \& Davidson, R. J. (1979). Low-anxious, highanxious, and repressive coping styles. Psychometric patterns and behavioral and physiological responses to stress. Journal of Abnormal Psychology, 88(4), 369-380. doi: 10.1037/0021-843X.88.4.369

Weintraub, W. (1989). Verbal Behavior in Everyday Life. New York, NY: Springer.

Weintraub, W., \& Aronson, H. (1974). The application of verbal behavior analysis to the study of psychological defense mechanisms. Archives of General Psychiatry, 30(3), 297-300.

Wrześniewski, K., Sosnowski, T., \& Matusik, D. (2002). Inwentarz Stanu i Cechy Lęku STAI. [STAI, State-Trait Anxiety Inventory]. Warszawa: Pracownia Testów Psychologicznych PTP.

Young, C. C., \& Dietrich, M. S. (2015). Stressful life events, worry and rumination predict depressive and anxiety symptoms in young adolescents. Journal of Child and Adolescent Psychiatric Nursing, 28(1), 35-42. doi: 10.1111/ jcap. 12102

Zinczuk J. (2008). Koherencja komponentów reakcji emocjonalnej a style radzenia sobie z bodźcami zagrażającymi - raport z badań [Coherence of Components of Emotional Reaction and Styles of Coping with Threatening Stimuli]. Psychologia - Etologia - Genetyka, 17, 59-88.

Zinczuk, J., \& Draheim, S. E. (2009). Represywny styl radzenia sobie z bodźcami zagrażającymi a samooszukiwanie [The repressive style of coping with threatening stimuli vs self-deception]. Czasopismo Psychologiczne, 15(1), 23-41.

Zinczuk-Zielazna, J., \& Obrębska, M. (2016). Styles of coping with threatening stimuli and level of dogmatism in texts as an indicator of anxiety in situations of social exposure. Polish Psychological Bulletin, 47(4), 402-411.

Zimbardo, P. G., Mahl, G. F. \& Barnard, J. W. (1963). The measurement of speech 
disturbance in anxious children. Journal of Speech \& Hearing Disorders, 28(4), 362-370.

Zimmermann, J., Brockmeyer, T., Hunn, M., Schauenburg, H., \& Wolf, M. (2017). First-person pronoun use in spoken language as a predictor of future depressive symptoms: preliminary evidence from a clinical sample of depressed patients. Clinical Psychology \& Psychotherapy, 24(2), 384-391. doi: $10.1002 /$ cpp.2006 